Article

\title{
Copper-Doped Cobalt Spinel Electrocatalysts Supported on Activated Carbon for Hydrogen Evolution Reaction
}

\author{
Jhony Xavier Flores-Lasluisa ${ }^{1}$, Javier Quílez-Bermejo ${ }^{2}$, Ana Cristina Ramírez-Pérez ${ }^{1}{ }^{\circledR}$, \\ Francisco Huerta ${ }^{3}$, Diego Cazorla-Amorós ${ }^{2} \mathbb{D}$ and Emilia Morallón ${ }^{1, *} \mathbb{D}$ \\ 1 Departamento de Química Física e Instituto Universitario de Materiales, Universidad de Alicante. Ap. 99, \\ E-03080 Alicante, Spain; jhonyxavier.jf@gmail.com (J.X.F.-L.); anacrami@gmail.com (A.C.R.-P.) \\ 2 Departamento de Química Inorgánica e Instituto Universitario de Materiales, Universidad de Alicante. Ap. \\ 99, E-03080 Alicante, Spain; javiquilezbermejo@gmail.com (J.Q.-B.); cazorla@ua.es (D.C.-A.) \\ 3 Departamento de Ingeniería Textil y Papelera, Universitat Politècnica de Valencia. Plaza Ferrandiz y \\ Carbonell, 1. E-03801 Alcoy, Spain; frahuear@txp.upv.es \\ * Correspondence: morallon@ua.es
}

Received: 28 February 2019; Accepted: 17 April 2019; Published: 20 April 2019

\begin{abstract}
The development of electrocatalysts based on the doping of copper over cobalt spinel supported on a microporous activated carbon has been studied. Both copper-cobalt and cobalt spinel nanoparticles were synthesized using a silica-template method. Hybrid materials consisting of an activated carbon (AC), cobalt oxide $\left(\mathrm{Co}_{3} \mathrm{O}_{4}\right)$, and copper-doped cobalt oxide $\left(\mathrm{CuCo}_{2} \mathrm{O}_{4}\right)$ nanoparticles, were obtained by dry mixing technique and evaluated as electrocatalysts in alkaline media for hydrogen evolution reaction. Physical mixtures containing 5, 10, and $20 \mathrm{wt} . \%$ of $\mathrm{Co}_{3} \mathrm{O}_{4}$ or $\mathrm{CuCo}_{2} \mathrm{O}_{4}$ with a highly microporous activated carbon were prepared and characterized by XRD, TEM, XPS, physical adsorption of gases, and electrochemical techniques. The electrochemical tests revealed that the electrodes containing copper as the dopant cation result in a lower overpotential and higher current density for the hydrogen evolution reaction.
\end{abstract}

Keywords: cobalt spinel; hydrogen evolution reaction; electrocatalysts; copper-cobalt oxide; microporous activated carbon

\section{Introduction}

The depletion of fossil fuels and the environmental problems caused by the emissions of greenhouse and other toxic gases during combustion have greatly encouraged researchers to develop technologies to extract energy from sustainable energy sources. Hydrogen is considered an ideal energy carrier to substitute current fuels due to its high specific energy, unlimited availability, the possibility of on-site production, and the evidence that hydrogen is the cleanest, non-polluting fuel [1]. Water splitting is suggested as the most appropriate way to produce hydrogen on a large scale, through the hydrogen evolution reaction (HER). Noble metal-based electrocatalysts, especially platinum-based materials, exhibit excellent activity toward the hydrogen evolution reaction (HER) but their commercial use is limited due to their low abundance and high-cost [2-4]. Therefore, the development of alternative non-noble metal electrocatalysts based on abundant and low-cost materials has attracted considerable attention to efficiently scale up the production of hydrogen. In order to obtain an efficient electrocatalyst towards HER, several specific properties are desirable, such as low hydrogen overpotential, no potential drift with time, good chemical and electrochemical stability, high adhesion to the support, high tolerance to poisoning by impurities, no environmental problems in the manufacturing process, and straightforward preparation at a low cost/lifetime ratio [5]. 
A wide variety of transition metal-based materials have been investigated towards HER and some of them exhibited promising results, such as dichalcogenides, metal-oxides, metal phosphides, carbides, borides, nitrides, metal alloys, and carbon-based compounds, among others [6-9]. In particular, cobalt-based compounds have emerged as interesting non-noble metal electrocatalysts because they show excellent performance for hydrogen adsorption [10]. It was shown that cobalt spinel catalysts (and those doped with another transition metal such as $\mathrm{Ni}, \mathrm{Fe}$, or $\mathrm{Cu}$ ) exhibit good activity towards HER [11-13]. Specifically, the presence of $\mathrm{Cu}$ in the spinel structure significantly enhances the electrochemical and physicochemical properties towards HER due to the presence of $\mathrm{Cu}_{2} \mathrm{O}$, which decreases the energy barrier for hydrogen adsorption [13-15]. Cobalt spinel materials were synthesized at a nano-size level and used for HER without any additional supporting material $[15,16]$. However, metal oxide nanoparticles can agglomerate, undergo deactivation of active sites, and the electrocatalyst activity can be lost. The role played by the support is, in consequence, essential for a good performance of electrocatalysts and carbon materials present several properties-such as high surface area, high conductivity or low-price-that make them ideal candidates to support these nanoparticles $[2,9,17,18]$.

In the present study, we propose the development of electrocatalysts based on the doping of copper over cobalt spinel supported by activated carbon. Both copper-cobalt and cobalt spinel nanoparticles were synthesized using a silica-template method. The nanoparticles were supported by activated carbon, with a high porosity development, through physical mixture by varying the concentration of the spinel nanoparticles. The structural, morphological, and electrochemical properties were investigated with transmission electron microscopy (TEM), X-ray photoelectronic spectroscopy (XPS), X-ray diffraction (XRD), $\mathrm{N}_{2}$-adsorption isotherms, cyclic voltammetry (CV), and their catalytic activity towards the hydrogen evolution reaction was also analysed by cyclic voltammetry.

\section{Experimental}

\subsection{Materials and Reagents}

Cobalt (II) nitrate hexahydrate $\left(\mathrm{Co}\left(\mathrm{NO}_{3}\right) \square 6 \mathrm{H}_{2} \mathrm{O}\right)$ (Sigma-Aldrich, ACS reagent, St. Louis, MO, USA), copper (II) nitrate trihydrate $\left(\mathrm{Cu}\left(\mathrm{NO}_{3}\right) \square 3 \mathrm{H}_{2} \mathrm{O}\right)$ (Sigma-Aldrich, $99 \%$, St. Louis, MO, USA), potassium hydroxide (KOH) (VWR Chemicals, $85 \mathrm{wt} \%$, Prague, Czech Republic), hydrochloric acid (HCl) (VWR Chemicals, 37\% vol, Fontenay-sous-Bois, France), poly(tetrafluoroethylene) (PTFE) (Sigma-Aldrich, $60 \mathrm{wt}$ \%, St. Louis, MO, USA), ethanol (VWR Chemicals, 96\% vol, Fontenay-sous-Bois, France), and silica xerogel (Sigma-Aldrich, TLC high-purity grade, St. Louis, MO, USA). All the reagents were used without any further purification process.

\subsection{Synthesis Procedure}

The activated carbon (AC) was prepared from a Spanish anthracite via chemical activation with $\mathrm{KOH}$, following the procedure described elsewhere [19]. Briefly, the AC was synthesized by a chemical activation with $\mathrm{KOH}$ using an activating agent:anthracite ratio of 3:1 and by heating in a $\mathrm{N}_{2}$ atmosphere $(400 \mathrm{~mL} / \mathrm{min})$ from room temperature to $750{ }^{\circ} \mathrm{C}$ at a heating rate of $5{ }^{\circ} \mathrm{C} \cdot \mathrm{min}^{-1}$. The maximum temperature was kept for $2 \mathrm{~h}$. After that, the AC was washed several times with a $5 \mathrm{M} \mathrm{HCl}$ solution and with distilled water until free of chloride ions, and then dried at $110^{\circ} \mathrm{C}$ for $12 \mathrm{~h}$.

$\mathrm{Co}_{3} \mathrm{O}_{4}$ nanoparticles were prepared by a nanocasting method with a commercial silica xerogel template [20]. First, a $1.6 \mathrm{M}$ ethanolic solution of $\mathrm{Co}\left(\mathrm{NO}_{3}\right)_{2} \cdot 6 \mathrm{H}_{2} \mathrm{O}$ was used to fill the pores of the silica sacrificial template via the incipient wetness impregnation method. The solvent was evaporated to dryness at $80^{\circ} \mathrm{C}$. The impregnation-drying cycle was repeated three times to obtain a high loading of the cobalt salt, and then the material was heat-treated in the air up to $400{ }^{\circ} \mathrm{C}$ for $4 \mathrm{~h}$. After that, the cobaltite nanoparticles were obtained after dissolution of the silica template with $2 \mathrm{M} \mathrm{NaOH}$.

$\mathrm{CuCo}_{2} \mathrm{O}_{4}$ were synthesized with the same procedure as described above by using $\mathrm{Cu}\left(\mathrm{NO}_{3}\right)_{2} \cdot 3 \mathrm{H}_{2} \mathrm{O}$ as the copper salt precursor and $\mathrm{Cu}^{2+} / \mathrm{Co}^{2+}$ molar ratio of 0.5 . 
AC- $\mathrm{Co}_{3} \mathrm{O}_{4}$ and $\mathrm{AC}-\mathrm{CuCo}_{2} \mathrm{O}_{4}$ materials were obtained by dry mixing the $\mathrm{AC}$ and the metal oxide powders in an agate mortar for $15 \mathrm{~min}$. Physical mixtures containing 5, 10, and $20 \mathrm{wt} . \%$ of either $\mathrm{Co}_{3} \mathrm{O}_{4}$ or $\mathrm{CuCo}_{2} \mathrm{O}_{4}$ were prepared. The electrocatalysts were named considering the weight percentage of each component of the mixture as follows: AC-Co5, AC-Co10, AC-Co20, AC-CuCo5, AC-CuCo10, and AC-CuCo20.

\subsection{Characterization Techniques}

The as-synthesized oxides were characterized by X-ray diffraction (XRD) using a $\mathrm{Cu} \mathrm{K} \alpha$ $(\lambda=0.1541 \mathrm{~nm})$ radiation source at a step of $0.05^{\circ} \mathrm{s}^{-1}$ in the $2 \theta$ range from $30^{\circ}$ to $80^{\circ}$ on a Bruker D8 (Billerica, USA) Advance diffractometer. Cell parameters were calculated by a computer program using the peak position obtained after fitting the experimental range with a pseudo-Voigt function per peak plus a background line. The line-broadening analysis was performed to determine the average crystallite size [21].

The X-ray photoelectron spectroscopy (XPS, Sussex, UK) analysis was done with VG-Microtech Multilab 3000 equipment by employing $\mathrm{MgK} \alpha(1253.6 \mathrm{eV})$ irradiation as the photo source. The analysis chamber pressure during scans was approximately $5 \times 10^{-7} \mathrm{~Pa}$ and the photoelectrons were collected into a hemispherical analyzer working in the constant energy mode at a pass energy of $50 \mathrm{eV}$. The $\mathrm{C} 1 \mathrm{~s}$ binding energy from adventitious hydrocarbon was taken as a charge reference and fixed at $284.6 \mathrm{eV}$. Peak energies were determined with an accuracy of $\pm 0.2 \mathrm{eV}$. Signal deconvolution of all XPS curves was done with mixed Gaussian-Lorentzian line shape functions after a nonlinear Shirley type background subtraction. The atomic ratio estimations were done, relating the peak areas after the background subtraction and were corrected relative to the corresponding atomic sensitivity factors. The metal oxides were characterized by transmission electron microscopy (TEM, JEOL-2010, $200 \mathrm{kV}$ accelerating voltage, Akishima, Japan). The samples for TEM analysis were prepared by putting the $\mathrm{Co}_{3} \mathrm{O}_{4}$ and $\mathrm{CuCo}_{2} \mathrm{O}_{4}$ powders on a standard copper grid. The bulk composition of perovskites was analysed by energy-dispersive X-ray spectroscopy (EDX) with Bruker XFlash 3001 equipment (Billerica, USA) attached to the scanning electron microscope (SEM, Hitachi, S3000N, Chiyoda, Japan).

Surface area and porosity of chemically activated carbon and the as-prepared composites were determined by physical adsorption of $\mathrm{N}_{2}\left(-196^{\circ} \mathrm{C}\right)$ and $\mathrm{CO}_{2}\left(0^{\circ} \mathrm{C}\right)$, using an automatic adsorption system (Autosorb-6, Quantrachrome, Boynton Beach, FL, USA). The samples were outgassed at $250^{\circ} \mathrm{C}$ under vacuum for $4 \mathrm{~h}$. Nitrogen adsorption results were employed to calculate Brunauer-Emmett-Teller (BET) surface area values and Dubinin-Radushkevich (DR) micropore volumes (VDR N 2 ) [22,23]. The $\mathrm{CO}_{2}$ adsorption data at these conditions is used to determine the narrow micropore volume (i.e., pores below $1 \mathrm{~nm}$ ) [24]. The pore size distribution of the silica xerogel was determined from the $\mathrm{N}_{2}$ adsorption-desorption isotherm, applying the Barrett-Joyner-Halenda (BJH) method to the desorption branch [25].

\subsection{Electrochemical Measurements}

The electrochemical performance of the different electrodes was assessed by cyclic voltammetry (CV) at $2 \mathrm{mV} \mathrm{s}^{-1}$ in a standard three-electrode cell (Figure S1) in a $0.1 \mathrm{M} \mathrm{KOH}$ solution. The working electrodes were prepared by mixing in an agate mortar $90 \mathrm{wt} . \%$ as-prepared materials, $5 \mathrm{wt} . \%$ acetylene black, and $5 \mathrm{wt} . \%$ PTFE. The resulting homogenous paste-like material was cold rolled to obtain electrodes of $1 \mathrm{~cm}^{2}$ and around $7 \mathrm{mg}$. After that, the paste film was placed on a stainless-steel mesh, which was used as a current collector, by pressing the electrode onto the mesh under 2 ton for $5 \mathrm{~min}$. A platinum wire was used as a counter electrode and a $\mathrm{Ag} / \mathrm{AgCl}$ electrode as a reference electrode. However, all potentials were referred to as a reversible hydrogen electrode (RHE). The electrochemical experiments were performed with a VMP3-BioLogic potentiostat, controlled by EC-Lab software. 
To calculate the gravimetric capacitance the following equation was employed:

$$
C=\frac{\int_{E_{1}}^{E_{2}} i(E) d E}{(E 2-E 1) m v},
$$

where $E_{1}$ and $E_{2}$ are the upper $\left(E_{2}\right)$ and lower $\left(E_{1}\right)$ potential limits in which the charge is calculated from the voltammogram, $m$ is the mass of the working electrode, and $v$ is the scan rate.

\section{Results and Discussion}

\subsection{Structural and Morphological Characterization}

The crystal structure of the nanoparticles synthesized by the silica template method was analyzed by $\mathrm{X}$-ray diffraction. Figure 1 shows the $\mathrm{X}$-ray powder diffraction patterns of cobaltite and copper cobaltite nanoparticles. The diffractograms of the as-prepared $\mathrm{Co}_{3} \mathrm{O}_{4}$ and $\mathrm{CuCo}_{2} \mathrm{O}_{4}$ powders exhibit reflection peaks at Bragg angles of ca. $31.25^{\circ}, 36.70^{\circ}, 44.45^{\circ}, 55.27^{\circ}, 59.21^{\circ}$, and $65.35^{\circ}$. These diffraction peaks match well with the (220), (311), (400), (442), (511), and (440) crystal planes of a cubic spinel cobaltite and a cubic spinel copper cobaltite (Fd3m [227] space group).

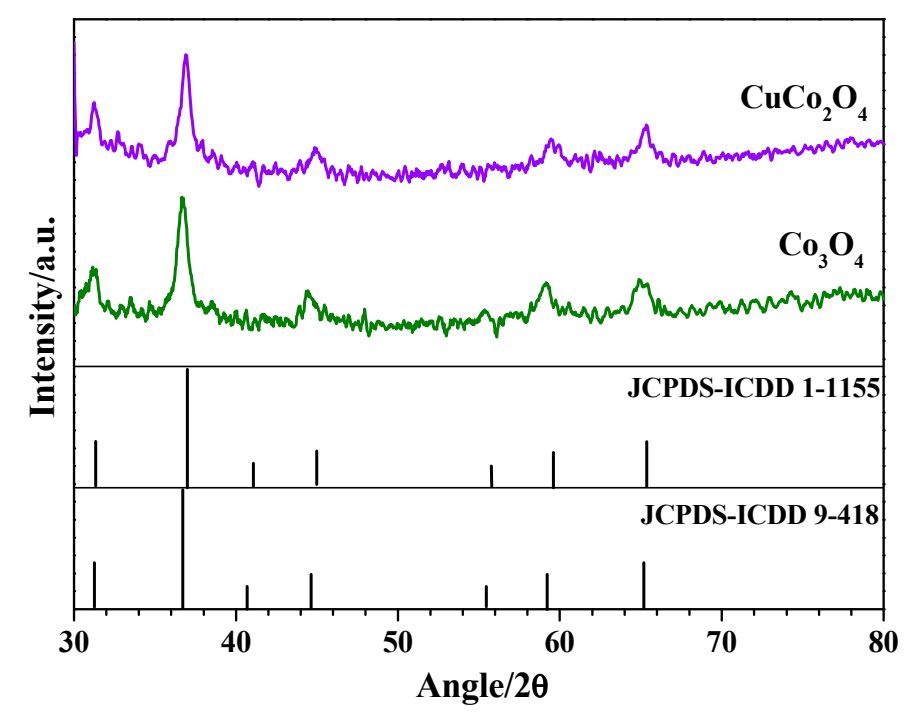

Figure 1. X-ray diffraction patterns of $\mathrm{CuCo}_{2} \mathrm{O}_{4}$ and $\mathrm{Co}_{3} \mathrm{O}_{4}$ nanoparticles.

Both the position and the intensities of the diffraction peaks agree with the data given in the International Centre for Diffraction Data (ICDD) cards for pure $\mathrm{Co}_{3} \mathrm{O}_{4}$ (JCPDS-ICDD 9-418 file) and pure $\mathrm{CuCo}_{2} \mathrm{O}_{4}$ (JCPDS-ICDD 1-1155 file). Moreover, the diffraction peaks for $\mathrm{CuCo}_{2} \mathrm{O}_{4}$ are slightly shifted to higher $2 \theta$ values with respect to the corresponding peaks in $\mathrm{Co}_{3} \mathrm{O}_{4}$. The incorporation of $\mathrm{Cu}$ ions, small atoms with respect to the $\mathrm{Co}$, into the octahedral sites of the cubic spinel $\mathrm{Co}_{3} \mathrm{O}_{4}$ structure contracts the lattice parameter. The lattice parameter $(a)$ and the unit cell volume $(V)$ of the as-synthesized cobalt oxides were calculated by Bragg equation for face-centered cubic crystals using the (220), (311), (400), (511), and (440) facets of the spinels. In addition, the coherence length of crystalline domains (i.e., crystallite size) was estimated by the Debye-Scherrer equation [20]. The unit cell parameters and the crystallite size of the oxides are summarized in Table 1. 
Table 1. Cell parameters and crystallite size of the as-prepared oxide nanoparticles calculated from diffraction patterns.

\begin{tabular}{|c|c|c|c|c|}
\hline Sample & $\begin{array}{c}\text { a }(\AA) \\
\text { ICDD Cards }\end{array}$ & a $(\AA)$ & V (Å3) & dc (nm) \\
\hline $\mathrm{Co}_{3} \mathrm{O}_{4}$ & 8.09 & 8.10 & 532.72 & 13 \\
\hline $\mathrm{CuCo}_{2} \mathrm{O}_{4}$ & 8.06 & 8.07 & 526.47 & 14 \\
\hline
\end{tabular}

As can be noted, the crystallite size $\left(d_{c}\right)$ is very similar for both materials. Furthermore, the lattice parameter and the cell volume decrease when $\mathrm{Cu}$ ions incorporate into the cubic spinel structure of cobalt oxide, indicating that a single phase is formed. The lattice parameter of $\mathrm{CuCo}_{2} \mathrm{O}_{4}$ powder is very similar to that reported in the literature by Marsan et al. [26] and Gautier et. al [27]. However, this value is smaller than those reported by other authors (values ranging from 8.11 to 8.13 were reported) [28-31]. The difference could be ascribed to the preparation method used to synthesize the spinel $\mathrm{CuCO}_{2} \mathrm{O}_{4}$.

Since XRD does not detect crystal structures different from those attributed to the $\mathrm{CuCo}_{2} \mathrm{O}_{4}$ spinel, the SEM-EDS technique was employed to obtain a mapping of copper and cobalt elements. Figure S2 in the supporting information shows an SEM-EDX image of $\mathrm{CuCo}_{2} \mathrm{O}_{4}$ that confirms the lack of phase segregation. Therefore, it was concluded that pure $\mathrm{CuCo}_{2} \mathrm{O}_{4}$ was synthesized with this method.

The morphology of the as-prepared $\mathrm{Co}_{3} \mathrm{O}_{4}$ and $\mathrm{CuCo}_{2} \mathrm{O}_{4}$ nanoparticles was evaluated by TEM (Figure 2). The micrographs show that both samples are composed of irregular nanoparticles of about $12 \mathrm{~nm}$ in size, in close agreement with the crystallite size determined by the Debye-Scherrer equation. The silica template exhibits mesoporosity in the 3-13 nm range (Figure S3), according to the pore-size distribution obtained by the $\mathrm{BJH}$ method from the nitrogen isotherm, being the maximum of the distribution at around $9 \mathrm{~nm}$ (Figure S3). Hence, as it was pointed out in previous works [20,32], the formation of nanoparticles takes place within the confined space provided by the mesoporous channels of the silica template.

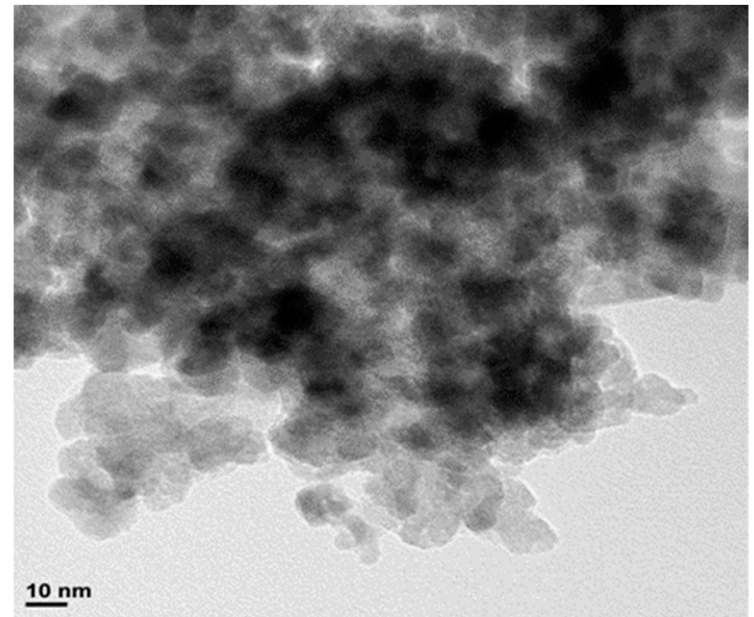

(a)

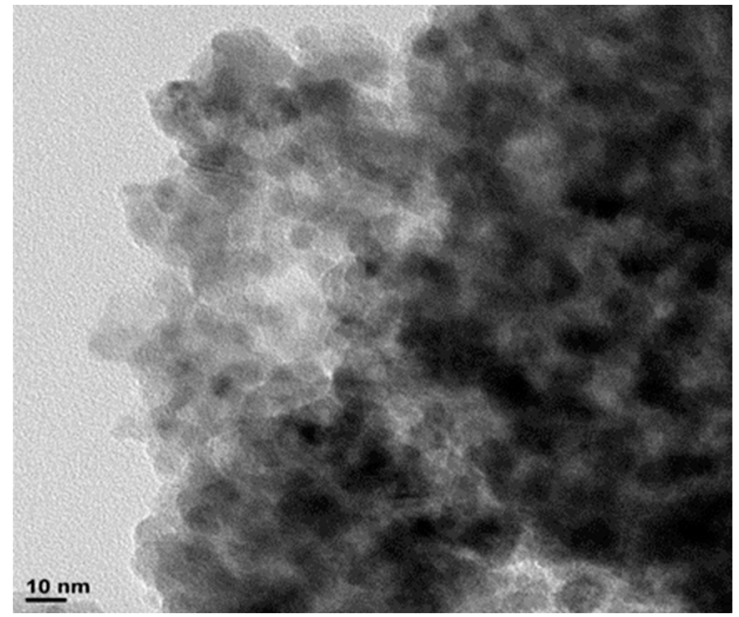

(b)

Figure 2. Transmission electron microscopy (TEM) images of (a) $\mathrm{Co}_{3} \mathrm{O}_{4}$ and (b) $\mathrm{CuCo}_{2} \mathrm{O}_{4}$ nanoparticles.

\subsection{Surface Analysis}

The surface chemical composition and the oxidation state of cobalt and copper ions in the cubic spinel powders were investigated by XPS analysis. In Figure 3, $\mathrm{Co} 2 \mathrm{p}$ and $\mathrm{Cu} 2 \mathrm{p}$ spectra recorded from $\mathrm{Co}_{3} \mathrm{O}_{4}$ and $\mathrm{CuCo}_{2} \mathrm{O}_{4}$ samples are displayed, whereas the binding energy of the photoemission lines is reported in Table 2. 

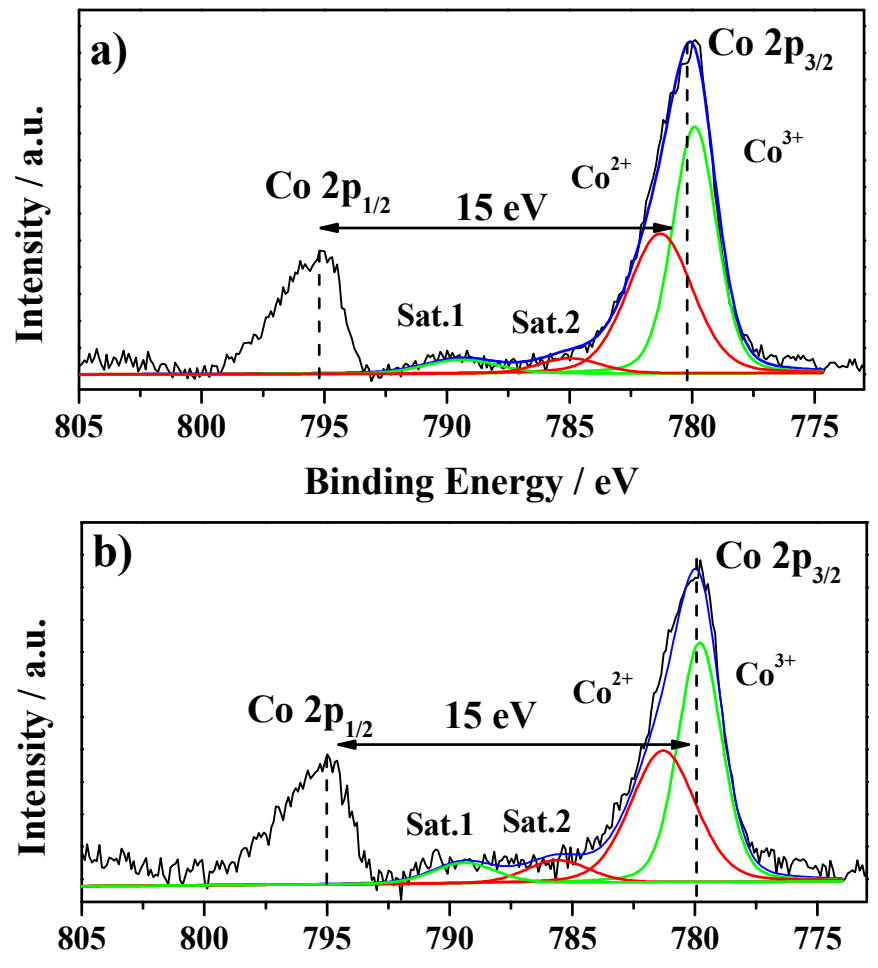

Binding Energy / eV

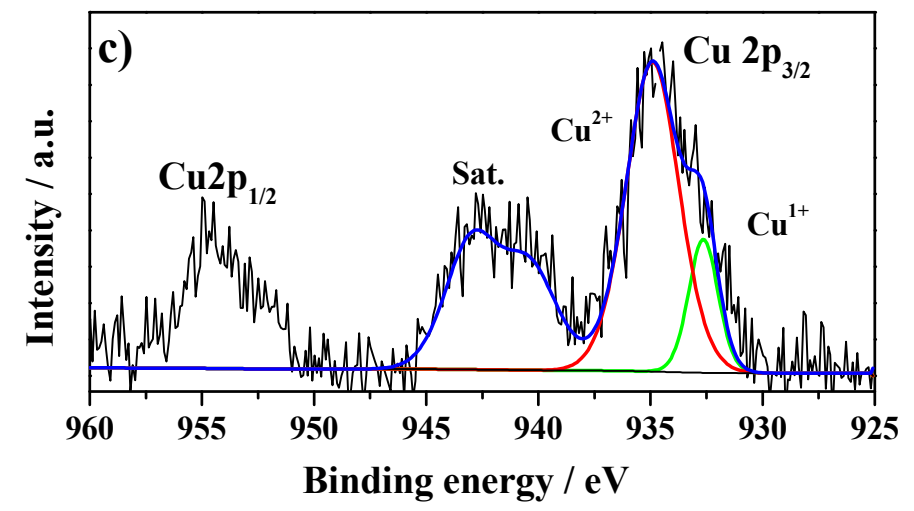

Figure 3. X-ray photoelectron spectra of $\mathrm{Co} 2 \mathrm{p}$ for (a) $\mathrm{Co}_{3} \mathrm{O}_{4}$ and (b) $\mathrm{CuCo}_{2} \mathrm{O}_{4}$, and (c) $\mathrm{Cu} 2 \mathrm{p}$ for $\mathrm{CuCO}_{2} \mathrm{O}_{4}$.

Table 2. Binding energies of $\mathrm{Co} 2 \mathrm{p}$ and $\mathrm{Cu} 2 \mathrm{p}$ and surface composition obtained from X-ray photoelectronic spectroscopy (XPS) spectra of $\mathrm{Co}_{3} \mathrm{O}_{4}$ and $\mathrm{CuCo}_{2} \mathrm{O}_{4}$ nanoparticles.

\begin{tabular}{cccccccccccc}
\hline \multirow{2}{*}{ Sample } & \multicolumn{4}{c}{$\mathrm{Co} \mathbf{2 p}(\mathrm{eV})$} & \multicolumn{4}{c}{$\mathrm{Cu} \mathbf{2 p}(\mathrm{eV})$} & \multicolumn{3}{c}{$\begin{array}{c}\text { Surface Atomic } \\
\text { Composition (at.\%) }\end{array}$} \\
\cline { 2 - 13 } & $\mathbf{2} \mathbf{p}_{3 / 2}$ & $\mathbf{2} \mathbf{p}_{1 / 2}$ & Sat. 1 & Sat. 2 & $\mathbf{2} \mathbf{p}_{3 / 2}$ & $\mathbf{2} \mathbf{p}_{1 / 2}$ & Sat. & $\mathbf{I}_{\text {sat }} / \mathbf{I}_{\text {main }}$ & $\mathbf{C o}$ & $\mathbf{C u}$ & $\mathbf{C u} / \mathbf{C o}$ \\
\hline $\mathrm{Co}_{3} \mathbf{O}_{4}$ & 780.2 & 795.2 & 789.4 & 785 & - & - & - & - & 5.1 & - & - \\
$\mathbf{C u C o}_{2} \mathbf{O}_{4}$ & 779.9 & 794.9 & 789.4 & 785.6 & 934.9 & 954.9 & 942.4 & 0.50 & 3.9 & 1.7 & 0.44 \\
\hline
\end{tabular}

The Co 2p core-level spectrum of $\mathrm{Co}_{3} \mathrm{O}_{4}$ spinel (Figure 3a) shows two asymmetric main peaks separated by a spin-orbit splitting energy of $15 \mathrm{eV}$, characteristic of a mixture of $\mathrm{Co}^{2+}$ and $\mathrm{Co}^{3+}$ ions [30,33]. The Co $2 \mathrm{p}_{3 / 2}$ peak is centered at $780.2 \mathrm{eV}$ and can be deconvoluted into two peaks at 779.9 and $781.3 \mathrm{eV}$. The first peak is associated with the $\mathrm{Co}^{3+}$ that it is contained in octahedral oxygen coordination and shows a satellite peak at $9.5 \mathrm{eV}$ above the main $2 \mathrm{p}_{3 / 2}$ line. The second peak is related 
to $\mathrm{Co}^{2+}$ with tetrahedral coordination and shows a satellite peak above $3.6-6.5 \mathrm{eV}$ above the main $2 \mathrm{p}_{3 / 2}$ line $[34,35]$.

The Co $2 \mathrm{p}$ spectra of $\mathrm{CuCo}_{2} \mathrm{O}_{4}$ is shown in Figure $3 \mathrm{~b}$ and reveals that the $\mathrm{Co} 2 \mathrm{p}_{3 / 2}$ and $\mathrm{Co}$ $2 \mathrm{p}_{1 / 2}$ peaks appear at slightly lower binding energies than those of $\mathrm{Co}_{3} \mathrm{O}_{4}$. The $\mathrm{Co} 2 \mathrm{p}_{3 / 2}$ signal can again be deconvoluted into two peaks centered at 779.8 and $781.3 \mathrm{eV}$ that correspond to $\mathrm{Co}^{3+}$ and $\mathrm{Co}^{2+}$, respectively. According to Fierro et al. [36], the binding energy (BE) shifts to lower values in copper-cobalt oxides because of a change in the cation distribution at the spinel surface when $\mathrm{Co}^{2+}$ is replaced by $\mathrm{Cu}^{2+}$ ions into the spinel lattice.

The $\mathrm{Cu} 2 \mathrm{p}$ core-level spectrum of the $\mathrm{CuCo}_{2} \mathrm{O}_{4}$ is characterized by two main peaks ascribed to $\mathrm{Cu}$ $2 p_{3 / 2} \mathrm{Cu} 2 p_{1 / 2}$ photoemission lines and a strong satellite signal between them (Figure $3 c$ ). The $\mathrm{Cu}-2 p_{3 / 2}$ is characterized by an asymmetric peak centered at $934.9 \mathrm{eV}$ with an intense satellite peak at $942.4 \mathrm{eV}$, and the $\mathrm{Cu} 2 \mathrm{p}_{1 / 2}$ component is characterized by a peak at ca. $954.9 \mathrm{eV}$. The peak at $934.9 \mathrm{eV}$ is assigned to octahedral $\mathrm{Cu}^{2+}$, whereas the peak located at a BE of $932.7 \mathrm{eV}$ can be attributed to tetrahedral $\mathrm{Cu}^{+}$, which comes from the recognized X-ray induced reduction of $\mathrm{Cu}^{2+}$ to $\mathrm{Cu}^{+}$in the presence of adventitious carbon $[26,28,30,31,36]$. Therefore, the separation of approximately $20.0 \mathrm{eV}$ between the main $\mathrm{Cu} 2 \mathrm{p}$ peaks is indicative of the existence of an open $3 \mathrm{~d}^{9}$ shell of $\mathrm{Cu}^{2+}$ [37]. In addition, the $\mathrm{I}_{\mathrm{sat}} / \mathrm{I}_{\text {main }}$ ratio is similar to the values reported in the literature for $\mathrm{CuO}$ [38] and indicates that $\mathrm{Cu}^{2+}$ ions on the surface of the inverse spinel adopt mainly octahedral geometry as that of $\mathrm{CuO}$. The $\mathrm{Co}_{3} \mathrm{O}_{4}$ adopt a normal spinel crystal structure, which can be considered as a face-centred cubic (fcc) packing of oxygen anions, with $\mathrm{Co}(\mathrm{III})$ filling half the octahedral interstitial sites and $\mathrm{Co}(\mathrm{II})$ filling one-eighth of the tetrahedral sites. The substitution of Co ions by foreign divalent transition metals is known to promote an inhomogeneous distribution of cations and produce a partially inverted spinel structure, with foreign and cobalt ions occupying both octahedral and tetrahedral sites. In the $\mathrm{CuCo}_{2} \mathrm{O}_{3}$, the copper cation is preferentially positioned in an octahedral position, with the ratio $\mathrm{Cu}$ (II) tetrahedral to $\mathrm{Cu}$ (II) octahedral at around 0.4 [31].

Table 2 includes also the surface composition of the as-synthesized oxide materials and, as can be noted, the surface of the copper-cobalt oxide exhibits a concentration of both cations close to the expected Co:Cu ratio (2:1).

\subsection{Textural Characterization of As-prepared Materials}

As is shown in Figure S4, the activated carbon derived from the Spanish anthracite and the hybrid materials both exhibit a type I isotherm for $\mathrm{N}_{2}$ adsorption, which is characteristic of microporous solids. The BET surface area and the micropore volumes calculated from $\mathrm{N}_{2}$ adsorption data at $-196^{\circ} \mathrm{C}$ $\left[\mathrm{V}_{\mathrm{DR}}\left(\mathrm{N}_{2}\right)\right]$ and $\mathrm{CO}_{2}$ adsorption data at $0{ }^{\circ} \mathrm{C}\left[\mathrm{V}_{\mathrm{DR}}\left(\mathrm{CO}_{2}\right)\right]$ are collected in Table 3.

The BET surface area and the micropore volumes of the cobalt oxide-activated carbon and copper-cobalt oxide-activated carbon hybrid materials (AC-Cox and AC-CuCox) were measured in order to evaluate the influence of the oxide content on the porosity of the activated carbon. It can be observed that the electrocatalysts present lower BET surface area and micropore volume compared to $\mathrm{AC}$, due to the partial blockage of pores producing values of surface area lower than the corresponding amount of AC. This means that these physical mixtures do not follow the dependence predicted by the rule of mixtures [39]. 
Table 3. Textural parameters obtained by $\mathrm{N}_{2}$ and $\mathrm{CO}_{2}$ isotherms for pristine AC-Cox and AC-CuCox hybrid materials. The last column shows the gravimetric capacitance derived from cyclic voltammetry experiments.

\begin{tabular}{|c|c|c|c|c|}
\hline Sample & $\begin{array}{c}S_{B E T} \\
\left(\mathrm{~m}^{2} \mathrm{~g}^{-1}\right)\end{array}$ & $\begin{array}{c}V_{D R} N_{2} \\
\left(\mathrm{~cm}^{3} \mathrm{~g}^{-1}\right)\end{array}$ & $\begin{array}{l}\mathrm{V}_{\mathrm{DR}} \mathrm{CO}_{2} \\
\left(\mathrm{~cm}^{3} \mathrm{~g}^{-1}\right)\end{array}$ & $\begin{array}{c}C \\
\left(\mathrm{~F} \mathrm{~g}^{-1}\right)\end{array}$ \\
\hline $\mathrm{AC}$ & 3310 & 1.30 & 0.76 & 262 \\
\hline $\mathrm{Co}_{3} \mathrm{O}_{4}$ & 112 [32] & - & - & 1 \\
\hline $\mathrm{CuCo}_{2} \mathrm{O}_{4}$ & $42[40]$ & - & - & 2 \\
\hline AC-Co5 & 2810 & 1.21 & 0.52 & 261 \\
\hline AC-Co10 & 2780 & 1.16 & 0.43 & 247 \\
\hline AC-Co20 & 2460 & 1.03 & 0.37 & 154 \\
\hline AC-CuCo5 & 2910 & 1.20 & 0.51 & 188 \\
\hline AC-CuCo10 & 2780 & 1.15 & 0.51 & 178 \\
\hline $\mathrm{AC}-\mathrm{CuCo} 20$ & 2220 & 0.92 & 0.40 & 174 \\
\hline
\end{tabular}

\subsection{Electrochemical Characterization and Catalytic Activity Towards HER}

The electrochemical behavior of the electrocatalysts was studied by cyclic voltammetry in a three-electrode cell configuration. First, we will address the response of electrocatalysts in the potential region preceding the hydrogen evolution reaction. In this way, Figure S5 displays cyclic voltammograms recorded between 0.00 and $0.80 \mathrm{~V}$ for each sample, where pseudo-capacitive responses associated mainly with the formation of the electrochemical double-layer can be observed in all cases. Figure S5a reveals that an increase in the cobalt content results in a progressive loss of voltammetric charge, and therefore of specific capacitance (see Table 3 for numerical values). These values agree with the decrease in the surface area obtained. Interestingly, Figure S5b shows that when copper is present the decrease in voltammetric charge is less significant compared to the Co-containing samples.

The electrocatalytic activity towards the hydrogen evolution reaction of all materials was studied in the same $0.1 \mathrm{M} \mathrm{KOH}$ solution. The results are displayed in Figure 4, where cyclic voltammograms recorded between $-0.40 \mathrm{~V}$ and $0.80 \mathrm{~V}$ have been depicted together. The activated carbon and the two pristine spinels (copper doped and non-doped) were included in the study for comparison purposes. It can be clearly observed that hybrid electrocatalysts obtained after mixing spinels and activated carbon improve the electrochemical performance compared to the un-supported spinels. In fact, the influence of carbon support in the catalytic activity of cobalt spinels towards the oxygen reduction reaction (ORR) was already carefully studied in chemical mixtures [41], although this has not been reported for HER. The favorable effect reported was attributed to better control over particle agglomeration induced by the supporting materials. Furthermore, Vulcan XC-72R has been used as an electric conductor to improve the catalytic properties of metal oxides [30]. According to previous studies [42], weak physical interactions exist between activated carbon and spinel nanoparticles that facilitate electron transfer between them, thus improving the overall electrical conductivity and enhancing the catalytic activity of these materials [30]. 

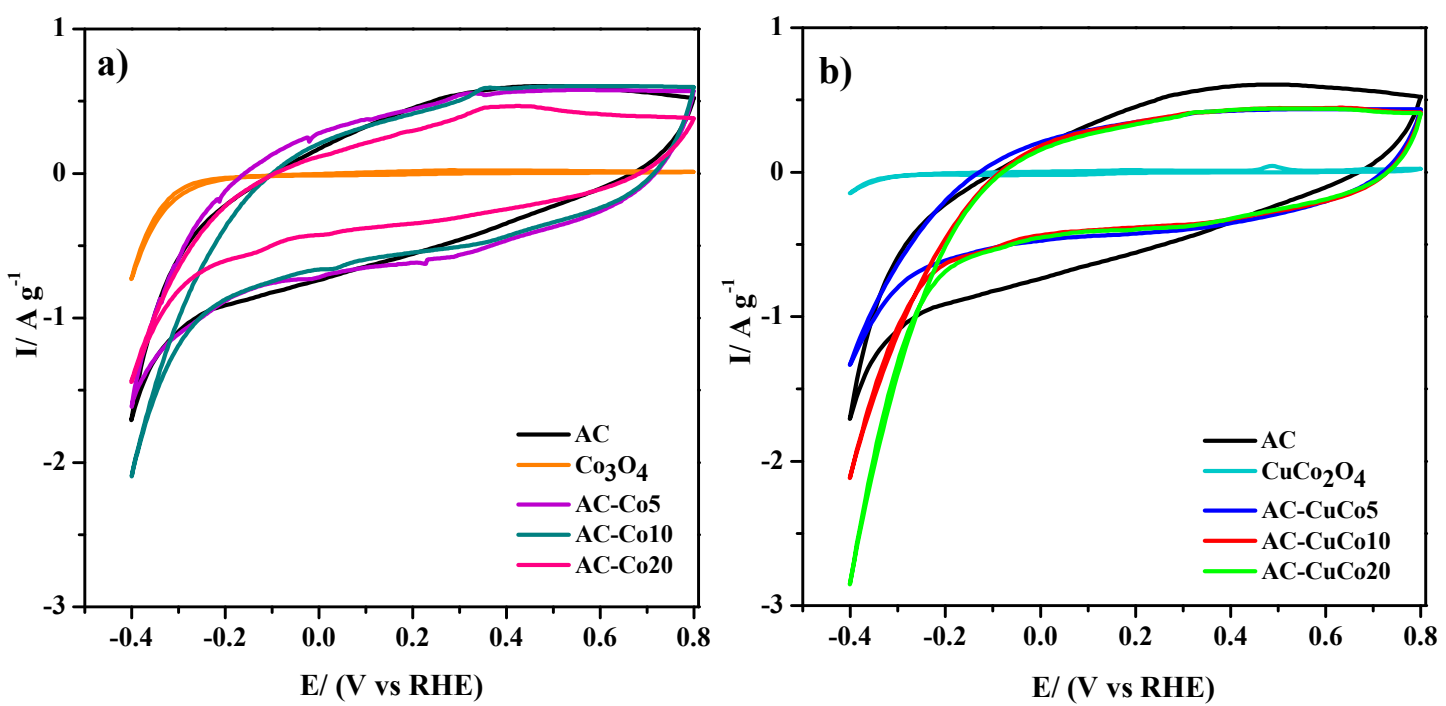

Figure 4. Cyclic voltammograms recorded in $0.1 \mathrm{M} \mathrm{KOH}$ showing the hydrogen evolution reaction at (a) undoped AC-Cox samples and (b) copper-doped AC-CuCox. Scan rate: $2 \mathrm{mV} \mathrm{s}^{-1}$.

Figure 4 shows the electrocatalytic activities of all samples, as examined by cyclic voltammetry. Moreover, Table 4 shows additional data on HER electrocatalysis. Again, the control over nanoparticle sizes and the enhancement in electrical conductivity explain the higher catalytic activity towards HER shown by both doped and undoped spinels supported on activated carbon. Moreover, the substitution in the octahedral position by $\mathrm{Cu}$ cations could also contribute to the increase in the electrocatalytic activity.

Table 4. Electrochemical parameters of the different materials tested in the hydrogen evolution reaction.

\begin{tabular}{|c|c|c|c|}
\hline Sample & $\begin{array}{c}\text { Tafel Slope } \\
\text { (mV/dec) }\end{array}$ & $\begin{array}{c}\text { Current }\left(\mathrm{A} \cdot \mathrm{g}^{-1}\right) \text { at } \\
-0.4 \text { V vs. RHE }\end{array}$ & $\begin{array}{c}\text { Current }\left(\mathrm{A} \cdot \mathrm{cm}^{-2}\right) \text { at } \\
-0.4 \mathrm{vs} . \mathrm{RHE}\end{array}$ \\
\hline $\mathrm{AC}$ & 416 & -1.65 & -9.5 \\
\hline $\mathrm{Co}_{3} \mathrm{O}_{4}$ & 132 & -0.75 & -5.2 \\
\hline $\mathrm{CuCo}_{2} \mathrm{O}_{4}$ & 124 & -0.15 & -1.0 \\
\hline AC-Co5 & 574 & -1.60 & -11.4 \\
\hline AC-Co10 & 457 & -2.10 & -12.8 \\
\hline AC-Co20 & 438 & -1.45 & -9.3 \\
\hline AC-CuCo5 & 454 & -1.30 & -8.1 \\
\hline AC-CuCo10 & 347 & -2.15 & -13.8 \\
\hline AC-CuCo20 & 300 & -2.85 & -14.6 \\
\hline
\end{tabular}

It is known that porous carbon materials can be used to store hydrogen by the electro-reduction of water in alkaline and neutral media $[43,44]$. The storage occurs through reversible $\mathrm{C}-\mathrm{H}$ bonds in which weakly bonded hydrogen is dominant in $\mathrm{KOH}$ [44]. The presence of the activated carbon can be beneficial to increase the concentration of adsorbed and dissociated hydrogen species, thus acting as a hydrogen reservoir. A tentative mechanism is presented, showing the hydrogen evolution reaction can occur in the presence of both materials. According to previous studies, HER can proceed through either Volmer-Tafel or Volmer-Heyrovsky pathways in basic mediums [45,46]:

$$
\begin{gathered}
\mathrm{H}_{2} \mathrm{O}+\mathrm{e}^{-} \rightarrow \mathrm{H}_{\mathrm{ads}}+\mathrm{OH}^{-} \text {(Volmer) } \\
\mathrm{H}_{\mathrm{ads}}+\mathrm{H}_{\mathrm{ads}} \rightarrow \mathrm{H}_{2} \text { (Tafel) } \\
\mathrm{H}_{2} \mathrm{O}+\mathrm{e}^{-} \rightarrow \mathrm{H}_{\mathrm{ads}}+\mathrm{OH}^{-} \text {(Volmer) }
\end{gathered}
$$




$$
\mathrm{H}_{\mathrm{ads}}+\mathrm{H}_{2} \mathrm{O}+\mathrm{e}^{-} \rightarrow \mathrm{H}_{2}+\mathrm{OH}^{-} \text {(Heyrovsky) }
$$

Both mechanisms involve the adsorption of $\mathrm{H}_{2} \mathrm{O}$ molecules and their subsequent splitting into adsorbed $\mathrm{H}$ atoms and $\mathrm{OH}^{-}$ions. In all the materials, the high values of the Tafel slope indicate that the rate determining step is the Volmer reaction. However, this Tafel slope decreases in the AC-copper oxide electrocatalysts in comparison with the AC, indicating the electrocatalytic effect of copper in the material. In addition, the microporous activated carbon might act as a hydrogen reservoir, providing $\mathrm{H}_{\mathrm{ads}}$ species to the oxide nanoparticles, where recombination into molecular hydrogen eventually occurs. This hypothesis needs further research to determine the role of the AC.

In summary, it seems that there is a relevant synergy between both the spinel nanoparticles and the carbon surface that results in an increase in the HER rate.

Besides the beneficial effect of the carbon support, Figure $4 \mathrm{~b}$ shows that the addition of copper as a dopant leads to a noticeable increase in the catalytic activity. Obviously, the hydrogen evolution reaction takes place also on the undoped cobalt spinel, but increasing the relative amount of this active material reveals an inconsistent effect on the current at $-0.4 \mathrm{~V}$ for hydrogen evolution (Figure $4 \mathrm{a}$ ). On the contrary, the presence of copper improves the overall voltammetric response and increases the cathodic current at $-0.4 \mathrm{~V}$ for this electrochemical reaction (Table 4). Such effects seem to be related to a change in the charge density at the spinel surface, which can chemisorb reactive water molecules more easily in the presence of copper ions due to the increase in oxygen vacancies and $\mathrm{Co}^{3+}$, thus facilitating the HER. A similar result was reported after doping with iron a cobalt spinel, for which the adsorption of water molecules was favored in $\mathrm{Fe}^{3+}$ in relation to $\mathrm{Co}^{2+}[12]$.

\section{Conclusions}

Hybrid materials, consisting of nanostructured cobalt or copper-doped cobalt spinels dispersed in a highly microporous activated carbon, were prepared by a dry physical mixing, characterized physicochemically, and tested as electrocatalysts for a hydrogen evolution reaction in an alkaline medium.

The use of a high surface area activated carbon as physical support improves the overall performance of cobalt-based spinel electrocatalysts. Activated carbon prevents the agglomeration of metal oxide particles and, in addition, also seems to play an active role in the HER. This is due to its well-known capacity to store hydrogen in alkaline conditions and also by an enhancement in the electrical conductivity of the oxide nanoparticles. As a consequence, a higher catalytic activity towards HER for the supported spinels compared to the un-supported materials is obtained.

It was demonstrated that the surface of copper-cobalt oxide particles shows a higher number of oxygen vacancies and $\mathrm{Co}^{3+}$. This surface composition results in active sites with a higher activity for hydrogen evolution than the undoped cobalt spinel, which eventually favors the formation of molecular hydrogen. Accordingly, the incorporation of copper as the dopant cation results in lower overpotential and higher current density for the target reaction.

From the point of view of a practical application, cobalt spinel doped with copper constitutes a promising alternative catalyst for HER, since the cost of this material is significantly lower than commercial platinum-based materials.

Supplementary Materials: The following are available online at http://www.mdpi.com/1996-1944/12/8/1302/s1, Figure S1: Configuration of a three-electrode cell, Figure S2: SEM-EDS elemental mapping of Co, Cu, and overlapped $\mathrm{Co}-\mathrm{Cu}$, Figure S3: BJH pore-size distribution of the silica template, Figure S4: Nitrogen adsorption isotherms at $-196{ }^{\circ} \mathrm{C}$ for all the hybrid materials: (a) AC-Cox and (b) AC-CuCox $(0 \leq x \leq 20$ wt.\%), Figure S5: Cyclic voltammograms recorded in $0.1 \mathrm{M} \mathrm{KOH}$ for all the hybrid materials within the pseudocapacitive potential region: (a) undoped AC-Cox samples and (b) copper-doped AC-CuCox samples. Scan rate: $2 \mathrm{mV} \mathrm{s}^{-1}$.

Author Contributions: Conceptualization, methodology, formal analysis, investigation, J.X.F.-L, J.Q.-B., A.C.R.-P., F.H., D.C.-A., E.M.; resources, E.M.; writing—original draft preparation, J.X.F.-L., J.Q.-B., F.H., E.M.; writing-review and editing, J.X.F.-L., J.Q.-B., A.C.R.-P., F.H., D.C.-A., E.M.; supervision, F.H., D.C.-A., E.M.; funding acquisition, E.M." 
Funding: This research was funded by MINECO and FEDER (MAT2016-76595-R).

Acknowledgments: J.X.F.-L. gratefully acknowledges MINECO for the FPI grant (BES-2017-081598).

Conflicts of Interest: The authors declare no conflict of interest.

\section{References}

1. Mazloomi, K.; Gomes, C. Hydrogen as an energy carrier: Prospects and challenges. Renew. Sustain. Energy Rev. 2012, 16, 3024-3033.

2. Xu, G.R.; Hui, J.J.; Huang, T.; Chen, Y.; Lee, J.M. Platinum nanocuboids supported on reduced graphene oxide as efficient electrocatalyst for the hydrogen evolution reaction. J. Power Sources 2015, 285, 393-399. [CrossRef]

3. Kemppainen, E.; Bodin, A.; Sebok, B.; Pedersen, T.; Seger, B.; Mei, B.; Bae, D.; Vesborg, P.C.K.; Halme, J.; Hansen, O.; et al. Scalability and feasibility of photoelectrochemical $\mathrm{H}_{2}$ evolution: the ultimate limit of $\mathrm{Pt}$ nanoparticle as an HER catalyst. Energy Environ. Sci. 2015, 8, 2991-2999. [CrossRef]

4. Raoof, J.B.; Ojani, R.; Kiani, A.; Rashid-Nadimi, S. Fabrication of highly porous Pt coated nanostructured $\mathrm{Cu}$-foam modified copper electrode and its enhanced catalytic ability for hydrogen evolution reaction. Int. J. Hydrogen Energy 2010, 35, 452-458. [CrossRef]

5. Jaccaud, M.; Leroux, F.; Millet, J.C. New chlor-alkali activated cathodes. Mater. Chem. Phys. 1989, 22, $105-119$. [CrossRef]

6. Mohammed-Ibrahim, J.; Xiaoming, S. Recent progress on earth abundant electrocatalysts for hydrogen evolution reaction (HER) in alkaline medium to achieve efficient water splitting - A review. J. Energy Chem. 2019, 34, 111-160. [CrossRef]

7. Zhou, W.; Jia, J.; Lu, J.; Yang, L.; Hou, D.; Li, G.; Chen, S. Recent developments of carbon-based electrocatalysts for hydrogen evolution reaction. Nano Energy 2016, 28, 29-43. [CrossRef]

8. Xiao, P.; Chen, W.; Wang, X. A Review of Phosphide-Based Materials for Electrocatalytic Hydrogen Evolution. Adv. Energy Mater. 2015, 5, 1-13.

9. Fei, H.; Yang, Y.; Peng, Z.; Ruan, G.; Zhong, Q.; Li, L.; Samuel, E.L.G.; Tour, J.M. Cobalt nanoparticles embedded in nitrogen-doped carbon for the hydrogen evolution reaction. ACS Appl. Mater. Interfaces 2015, 7, 8083-8087. [CrossRef] [PubMed]

10. Lupi, C.; Dell'Era, A.; Pasquali, M. Nickel-cobalt electrodeposited alloys for hydrogen evolution in alkaline media. Int. J. Hydrogen Energy 2009, 34, 2101-2106. [CrossRef]

11. Gao, X.; Zhang, H.; Li, Q.; Yu, X.; Hong, Z.; Zhang, X.; Liang, C.; Lin, Z. Hierarchical $\mathrm{NiCo}_{2} \mathrm{O}_{4}$ hollow microcuboids as bifunctional electrocatalysts for overall water-splitting. Angew. Chem. Int. Ed. 2016, 55, 6290-6294. [CrossRef]

12. Bandal, H.A.; Jadhav, A.R.; Tamboli, A.H.; Kim, H. Bimetallic iron cobalt oxide self-supported on Ni-Foam: An efficient bifunctional electrocatalyst for oxygen and hydrogen evolution reaction. Electrochim. Acta 2017, 249, 253-262. [CrossRef]

13. Kuang, M.; Han, P.; Wang, Q.; Li, J.; Zheng, G. CuCo Hybrid Oxides as Bifunctional Electrocatalyst for Efficient Water Splitting. Adv. Funct. Mater. 2016, 26, 8555-8561. [CrossRef]

14. Du, J.; Wang, J.; Ji, L.; Xu, X.; Chen, Z. A Highly Active and Robust Copper-Based Electrocatalyst toward Hydrogen Evolution Reaction with Low Overpotential in Neutral Solution. ACS Appl. Mater. Interfaces 2016, 8, 30205-30211. [CrossRef] [PubMed]

15. Jia, J.; Li, X.; Chen, G. Stable spinel type cobalt and copper oxide electrodes for $\mathrm{O}_{2}$ and $\mathrm{H}_{2}$ evolutions in alkaline solution. Electrochim. Acta 2010, 55, 8197-8206. [CrossRef]

16. Yan, X.; Tian, L.; He, M.; Chen, X. Three-Dimensional Crystalline/Amorphous $\mathrm{Co} / \mathrm{Co}_{3} \mathrm{O}_{4}$ Core/Shell Nanosheets as Efficient Electrocatalysts for the Hydrogen Evolution Reaction. Nano Lett. 2015, 15, 6015-6021. [CrossRef] [PubMed]

17. Peng, S.; Li, N.; Han, X.; Sun, W.; Srinivasan, M.; Mhaisalkar, S.G.; Cheng, F.; Yan, Q.; Chen, J.; Ramakrishna, S. Cobalt sulfide nanosheet/graphene/carbon nanotube nanocomposites as flexible electrodes for hydrogen evolution. Angew. Chem. Int. Ed. 2014, 53, 12594-12599.

18. Gao, G.; Lu, S.; Dong, B.; Xiang, Y.; Xi, K.; Ding, S. Mesoporous $\mathrm{Co}_{3} \mathrm{~V}_{2} \mathrm{O}_{8}$ nanoparticles grown on reduced graphene oxide as a high-rate and long-life anode material for lithium-ion batteries. J. Mater. Chem. A 2016, 4, 6264-6270. [CrossRef] 
19. Lillo-Ródenas, M.; Lozano-Castelló, D.; Cazorla-Amorós, D.; Linares-Solano, A. Preparation of activated carbons from Spanish anthracite I. Activation by KOH. Carbon 2001, 39, 741-749.

20. Berenguer, R.; Valdés-Solís, T.; Fuertes, A.B.; Quijada, C.; Morallón, E. Cyanide and Phenol Oxidation on Nanostructured $\mathrm{Co}_{3} \mathrm{O}_{4}$ Electrodes Prepared by Different Methods. J. Electrochem. Soc. 2008, 155, K110-K115. [CrossRef]

21. Montilla, F.; Morallón, E.; De Battisti, A.; Benedetti, A.; Yamashita, H.; Vázquez, J.L. Preparation and Characterization of Antimony-Doped Tin Dioxide Electrodes. Part 2. XRD and EXAFS Characterization. J. Phys. Chem. B 2004, 108, 5044-5050. [CrossRef]

22. Rouquerol, F.; Rouquerol, J.; Sing, K. Chapter 6 - Assessment of Surface Area. In Adsorption by Powders and Porous Solids: Principles, Methodology and Applications; Academic Press: London, UK, 1999; pp. 165-189.

23. Dubinin, M.M. The Potential Theory of Adsorption of Gases and Vapors for Adsorbents with Energetically Nonuniform Surfaces. Chem. Rev. 1960, 60, 235-241. [CrossRef]

24. Cazorla-Amorós, D.; Alcañiz-Monge, J.; de la Casa-Lillo, M.A.; Linares-Solano, A. $\mathrm{CO}_{2}$ As an Adsorptive To Characterize Carbon Molecular Sieves and Activated Carbons. Langmuir 1998, 14, 4589-4596.

25. Barrett, E.P.; Joyner, L.G.; Halenda, P.P. The Determination of Pore Volume and Area Distributions in Porous Substances. I. Computations from Nitrogen Isotherms. J. Am. Chem. Soc. 1951, 73, 373-380. [CrossRef]

26. Marsan, B.; Fradette, N.; Beaudoin, G. Physicochemical and Electrochemical Properties of $\mathrm{CuCo}_{2} \mathrm{O}_{4}$ Electrodes Prepared by Thermal Decomposition for Oxygen Evolution. J. Electrochem. Soc. 1992, 139, 1889-1896. [CrossRef]

27. Gautier, J.L.; Trollund, E.; Ríos, E.; Nkeng, P.; Poillerat, G. Characterization of thin $\mathrm{CuCo}_{2} \mathrm{O}_{4}$ films prepared by chemical spray pyrolysis. Study of their electrochemical stability by ex situ spectroscopic analysis. J. Electroanal. Chem. 1997, 428, 47-56. [CrossRef]

28. Vijayakumar, S.; Lee, S.H.; Ryu, K.S. Hierarchical $\mathrm{CuCo}_{2} \mathrm{O}_{4}$ nanobelts as a supercapacitor electrode with high areal and specific capacitance. Electrochim. Acta 2015, 182, 979-986. [CrossRef]

29. Chi, B.; Lin, H.; Li, J. Cations distribution of $\mathrm{Cu}_{\mathrm{x}} \mathrm{Co}_{3-\mathrm{x}} \mathrm{O}_{4}$ and its electrocatalytic activities for oxygen evolution reaction. Int. J. Hydrogen Energy 2008, 33, 4763-4768. [CrossRef]

30. De Koninck, M.; Poirier, S.-C.; Marsan, B. $\mathrm{Cu}_{\mathrm{x}} \mathrm{Co}_{3-\mathrm{x}} \mathrm{O}_{4}$ Used as Bifunctional Electrocatalyst. J. Electrochem. Soc. 2006, 153, A2103-A2110. [CrossRef]

31. La Rosa-Toro, A.; Berenguer, R.; Quijada, C.; Montilla, F.; Morallón, E.; Vázquez, J.L. Preparation and Characterization of Copper-Doped Cobalt Oxide Electrodes. J. Phys. Chem. B 2006, 110, 24021-24029. [CrossRef]

32. Valdés-Solís, T.; Marbán, G.; Fuertes, A.B. Preparation of Nanosized Perovskites and Spinels through a Silica Xerogel Template Route. Chem. Mater. 2005, 17, 1919-1922. [CrossRef]

33. Huang, Y.; Jiang, Y.; Zou, L.; Cheng, J.; Chi, B.; Pu, J.; Li, J. Ultrathin $\mathrm{CuCo}_{2} \mathrm{O}_{4}$ Nanosheets on Carbon Textiles as Flexible Cathodes for Bendable Lithium-Air Batteries. J. Electrochem. Soc. 2017, 164, A3896-A3902. [CrossRef]

34. Gautier, J.L.; Rios, E.; Gracia, M.; Marco, J.F.; Gancedo, J.R. Characterisation by X-ray photoelectron spectroscopy of thin $\mathrm{Mn}_{\mathrm{x}} \mathrm{Co}_{3-\mathrm{x}} \mathrm{O}_{4}(1 \geq \mathrm{x} \geq 0)$ spinel films prepared by low-temperature spray pyrolysis. Thin Solid Films 1997, 311, 51-57. [CrossRef]

35. Okamoto, Y.; Nakano, H.; Imanaka, T.; Teranishi, S. X-Ray Photoelectron Spectroscopic Studies of Catalysts-Supported Cobalt Catalysts—. Bull. Chem. Soc. Jpn. 1975, 48, 1163-1168. [CrossRef]

36. Fierro, G.; Lo Jacono, M.; Inversi, M.; Dragone, R.; Porta, P. TPR and XPS study of cobalt-copper mixed oxide catalysts: Evidence of a strong Co-Cu interaction. Top. Catal. 2000, 10, 39-48. [CrossRef]

37. Chusuei, C.C.; Brookshier, M.A.; Goodman, D.W. Correlation of relative X-ray photoelectron spectroscopy shake-up intensity with CuO particle size. Langmuir 1999, 15, 2806-2808. [CrossRef]

38. Frost, D.C.; Ishitani, A.; McDowell, C.A. X-ray photoelectron spectroscopy of copper compounds. Mol. Phys. 1972, 24, 861-877. [CrossRef]

39. Barranco, V.; Pico, F.; Ibañez, J.; Lillo-Rodenas, M.A.; Linares-Solano, A.; Kimura, M.; Oya, A.; Rojas, R.M.; Amarilla, J.M.; Rojo, J.M. Amorphous carbon nanofibres inducing high specific capacitance of deposited hydrous ruthenium oxide. Electrochim. Acta 2009, 54, 7452-7457. [CrossRef]

40. Serov, A.; Andersen, N.I.; Roy, A.J.; Matanovic, I.; Artyushkova, K.; Atanassov, P. $\mathrm{CuCo}_{2} \mathrm{O}_{4}$ ORR/OER Bi-Functional Catalyst: Influence of Synthetic Approach on Performance. J. Electrochem. Soc. 2015, 162, F449-F454. [CrossRef] 
41. Kostuch, A.; Gryboś, J.; Indyka, P.; Osmieri, L.; Specchia, S.; Sojka, Z.; Kruczała, K. Morphology and dispersion of nanostructured manganese-cobalt spinel on various carbon supports: The effect on the oxygen reduction reaction in alkaline media. Catal. Sci. Technol. 2018, 8, 642-655. [CrossRef]

42. Zhu, Y.; Zhou, W.; Shao, Z. Perovskite/Carbon Composites: Applications in Oxygen Electrocatalysis. Small 2017, 13, 1-25. [CrossRef] [PubMed]

43. Bleda-Martínez, M.J.; Pérez, J.M.; Linares-Solano, A.; Morallón, E.; Cazorla-Amorós, D. Effect of surface chemistry on electrochemical storage of hydrogen in porous carbon materials. Carbon 2008, 46, 1053-1059. [CrossRef]

44. Leyva-García, S.; Morallón, E.; Cazorla-Amorós, D.; Béguin, F.; Lozano-Castelló, D. New insights on electrochemical hydrogen storage in nanoporous carbons by in situ Raman spectroscopy. Carbon 2014, 69, 401-408. [CrossRef]

45. Jin, H.; Wang, J.; Su, D.; Pang, Z.; Wang, Y. In-situ cobalt-cobalt oxide / N-doped carbon hybrids as superior electrocatalysts for hydrogen and oxygen evolution. J. Am. Chem. Soc. 2015, 137, 2688-2694. [CrossRef]

46. Pennycook, S.J.; Guan, M.; Yang, J.; Tsai, M.-C.; Hu, Y.; Gong, M.; Zhou, W.; Zhou, J.; Hwang, B.-J.; Dai, H.; et al. Nanoscale nickel oxide/nickel heterostructures for active hydrogen evolution electrocatalysis. Nat. Commun. 2014, 5, 1-6.

(C) 2019 by the authors. Licensee MDPI, Basel, Switzerland. This article is an open access article distributed under the terms and conditions of the Creative Commons Attribution (CC BY) license (http://creativecommons.org/licenses/by/4.0/). 